\title{
Ultrasound in clinical setting of secondary hyperparathyroidism
}

\author{
Mario Meola ${ }^{1,2}$, Ilaria Petrucci ${ }^{1,2}$, Adamasco Cupisti ${ }^{2}$
}

\author{
${ }^{1}$ S. Anna School of Advanced Studies, University of Pisa, \\ Pisa - Italy \\ ${ }^{2}$ Nephrology Division, Department of Clinical and \\ Experimental Medicine, University of Pisa, Pisa - Italy
}

\section{Abstract}

Secondary hyperparathyroidism (sHPT) is one of the most common and serious complications of chronic kidney disease (CKD) and maintenance hemodialysis (MHD). In sHPT, the biology of parathyroid cells changes significantly toward diffuse and nodular hyperplasia. Diagnosis and treatment of sHPT are based on intact parathyroid hormone (i-PTH) serum levels and on the parameters of mineral metabolism. The morphological diagnosis of sHPT relies on 2 complementary imaging techniques: high-resolution ultrasonography with color Doppler imaging (US/CD) and ${ }^{99 m} \mathrm{Tc}-\mathrm{me}-$ thoxyisobutylisonitrile (MIBI) scintigraphy.

The main objective of this review is to stimulate nephrologists to use US/CD of the parathyroid glands during the progression of CKD in order to aid clinical, pharmacological and surgical strategies. The primary role of US/CD in sHPT should be to integrate the clinical diagnosis by defining the number and volume of hyperplastic glands, although the international guidelines do not state when and why to perform US/CD. This review also evaluates the role of US/CD in clinical follow-up and assessment of therapeutic response of sHPT, and it highlights how US/CD can evaluate the effect of therapy with phosphate binders, vitamin D or its analogues and calcimimetics, which are changing the natural history of sHPT and the frequency of parathyroidectomy. Evaluation of the morphological and vascular changes of hyperplastic parathyroids is useful to guide percutaneous ethanol injection therapy and to support clinical, pharmacological and surgical strategies. Epidemiological studies are needed to establish how US/CD could change the management of SHPT and why it should be repeated in patients with high levels of serum i-PTH.

Key words: Neck sonography, Parathyroid color-Doppler, Parathyroid hyperplasia, Parathyroid ultrasound, Secondary hyperparathyroidism

\section{INTRODUCTION}

Secondary hyperparathyroidism (SHPT) develops progressively during the course of chronic kidney disease (CKD). Hypocalcemia, phosphate retention and the related deficit in 1,25-dihydroxycholecalciferol $\left(1,25(\mathrm{OH})_{2} \mathrm{D}_{3}\right)$ stimulate the synthesis and release of parathyroid hormone (PTH) and fibroblast growth factor-23 (FGF-23) (1, 2). The enduring alterations of mineral metabolism caused by uremia and progressive loss of nephron mass are responsible of continuous stimulation of parathyroid cells. Cells biology changes so it induces cell hypertrophy-hyperplasia and the selection of cell clones with reduced calcium receptor $(\mathrm{CaR})$ and vitamin D receptor (VDR) density (1).

Glandular hyperplasia is at first polyclonal and widespread then monoclonal and nodular. In severe sHPT, parathyroid glands become less responsive to hormonal stimuli. This may trigger a disorder of cellular growth which can lead to tertiary or autonomous hyperparathyroidism $(3,4)$. Nodular hyperplasia does not involve all parathyroid glands, nor does it affect all patients with CKD equally; therefore, it can be assumed that genetic mechanisms are involved in its development, although the exact mechanisms are currently unknown (3, 5-7).

Nowadays, sHPT diagnosis is based on biochemical parameters of mineral metabolism because the identification of normal parathyroid glands is difficult with all imaging techniques. However, high-resolution sonography with color Doppler (US/CD), performed by skilled operators, can localize hyperplastic parathyroid glands. Indeed, hyperplastic glands become hypoechoic and well distinguished from the thyroid parenchyma due to their increased cellularity and reduction of adipose stromal tissue. US/CD is the only technique that measures volumetric variations of parathyroid glands, simultaneously providing semiquantitative parameters for glandular perfusion during the progression of $\operatorname{sHPT}(8,9)$. 


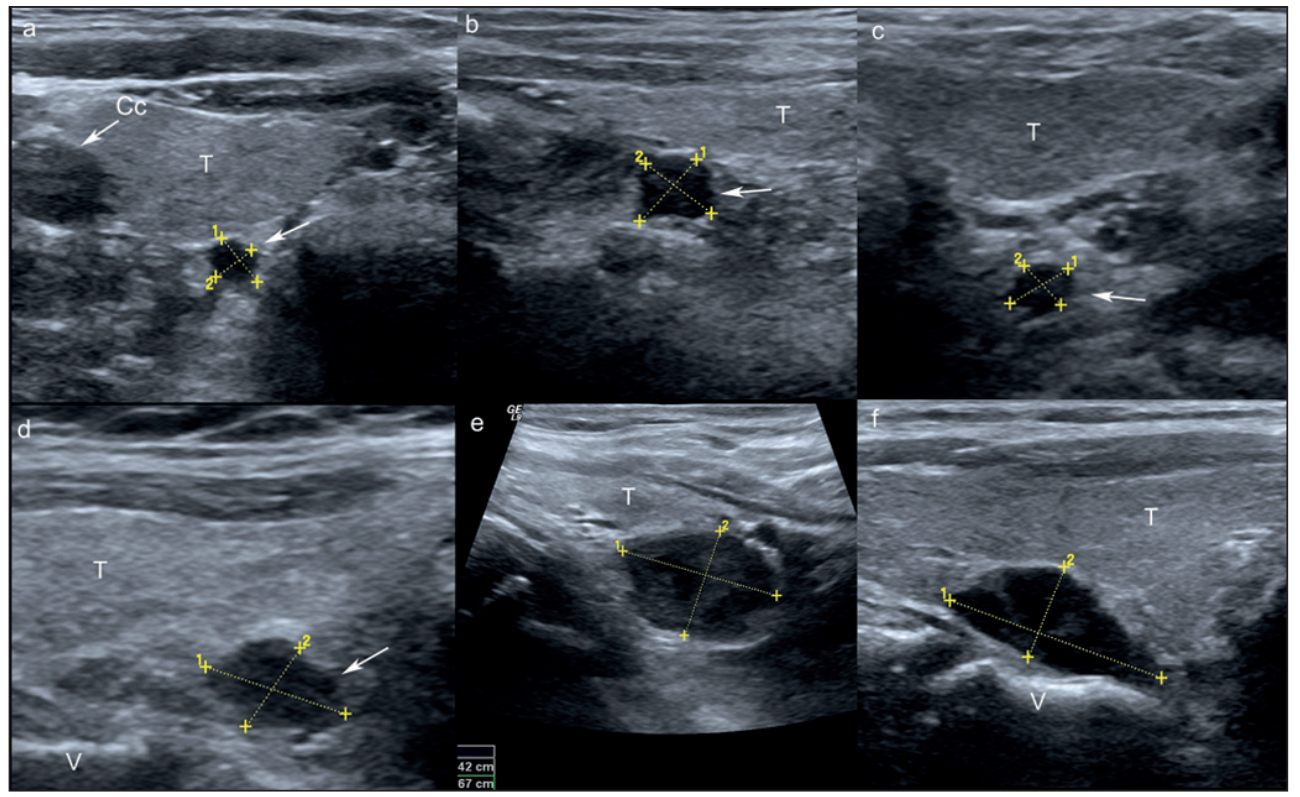

Fig. 1 - Parathyroid hyperplasia. a) Transversal plane on right thyroid lobe. b) Longitudinal plane and c) transversal plane on left thyroid lobe. Hyperplastic parathyroids (white arrows) appear as a clearly edged hypoechoic nodule, with a thin hyperechoic capsule. Gland diameters are 5-6 mm. d-f) Longitudinal scan on thyroid lodge. Nodular hyperplasia appears as a hypoechoic nodule (white arrows) with a thin hyperechoic capsule, a longaxis diameter $>1 \mathrm{~cm}$ and a volume $>500 \mathrm{~mm}^{3}$, behind the thyroid lobe. Histological analysis suggests that glands $<500 \mathrm{~mm}^{3}$ show diffuse or multinodular polyclonal hyperplasia, whereas glands $>500 \mathrm{~mm}^{3}$ present monoclonal nodular hyperplasia in $80 \%$ of cases. $\mathrm{T}=$ thyroid; $\mathrm{V}=$ cervical vertebra.
This review highlights the pivotal role of US/CD in diagnosis, clinical follow-up, therapeutic response to drugs, percutaneous alcoholization and presurgical assessment of sHPT.

\section{TABLE I}

ANATOMICAL CHARACTERISTICS OF PARATHYROID GLANDS $(10,11)$

\begin{tabular}{|c|c|}
\hline Number & $\begin{array}{l}\text { - Four glands ( } 2 \text { superior, } 2 \text { inferior). } \\
\text { They are small ( } 20-40 \mathrm{mg} \text { ) and have a } \\
\text { bean-like shape }\end{array}$ \\
\hline Development & $\begin{array}{l}\text { - Superior glands arise from the 4th } \\
\text { pharingeal pouch (PIV) } \\
\text { - Inferior glands arise from the 3rd phar- } \\
\text { ingeal pouch (PIII) }\end{array}$ \\
\hline Location & $\begin{array}{l}\text { PIV - Posterolateral profile of superior } \\
\text { thyroid pole (at the cricothyroidal carti- } \\
\text { lage junction, } 1 \mathrm{~cm} \text { above the intersec- } \\
\text { tion of the inferior thyroid artery and } \\
\text { the recurrent laryngeal nerve) } \\
\text { - PIII - More variable (near the lower } \\
\text { pole of the thyroid or between the } \\
\text { thyroid pole and the thymus horn) }\end{array}$ \\
\hline $\begin{array}{l}\text { Vascular } \\
\text { anatomy }\end{array}$ & $\begin{array}{l}\text { - PIV and PIII are supplied by the inferior } \\
\text { thyroid artery of thyreocervical trunk }\end{array}$ \\
\hline $\begin{array}{l}\text { Anatomical } \\
\text { anomalies }\end{array}$ & $\begin{array}{l}\text { - Absence of } 1 \text { parathyroid (i.e., }<4 \\
\text { glands): } 3 \% \text { of cases } \\
\text { - Accessory or supernumerary: } 13 \% \text { of } \\
\text { cases } \\
\text { - Ectopic glands: } 15 \%-29 \% \text { of cases }\end{array}$ \\
\hline
\end{tabular}

METHOdS, EQUIPMENT AND PARAMETERS TO BE CONSIDERED WHEN PERFORMING US/CD

Anatomical characteristics of parathyroid glands are summarized in Table I. Standard procedure for examination of the cervical region requires that patients are in a supine position, with their neck hyperextended and slightly deviated, first to the right and then to the left, to allow exploration of the laterocervical region, from the corner of the jaw to the superior mediastinum. High-resolution linear probes (7.5-14 MHz), extended field of view and compound harmonic imaging should be used to improve spatial resolution and B-mode image quality. CD sampling of glandular flow should be obtained with a transmission frequency of $3.8 \mathrm{MHz}$, a pulse repetition frequency $<800 \mathrm{kHz}$ and a medium-high color gain (i.e., 45-50 on a scale of 0-60) (12).

Normal parathyroid glands, which are rich in adipose cells, appear structurally similar to the thyroid parenchyma, making them difficult to distinguish even using high-resolution probes $(10,11,13)$. Primary or secondary cellular hyperplasia, however, makes the glands diffusely hypoechoic compared with the thyroid parenchyma, and well outlined by a thin hyperechoic edge. There is no defined size limit over which a parathyroid gland can be considered pathological, although a hypoechoic gland, well distinguished from the thyroid parenchyma and with 2 diameters $>5 \mathrm{~mm}$, is generally considered to be hyperplastic (14) (Fig. 1).

The major limit of US/CD is the operator-dependence whereas safety, repeatability, lower cost and the ability to assess the changes in glandular volume give US/CD a unique ad- 


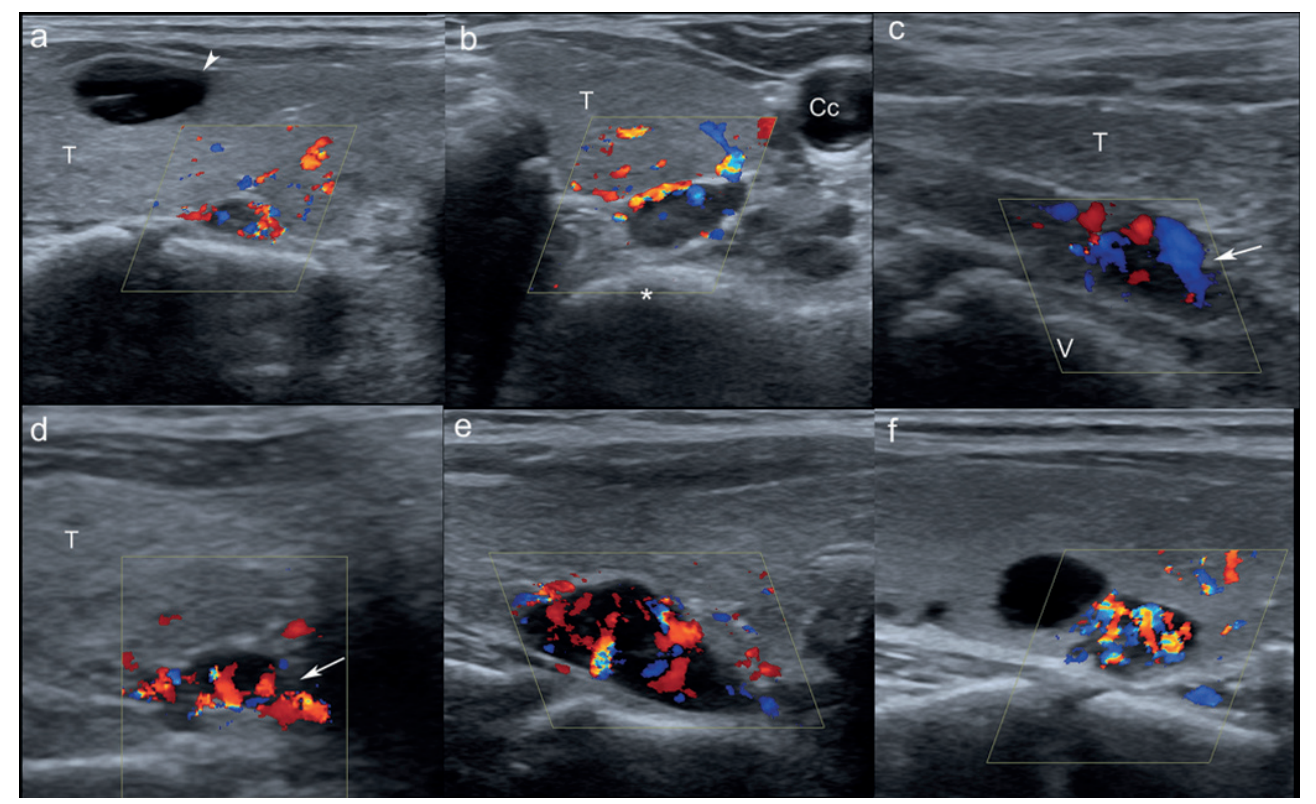

Fig. 2 - Vascular pattern of hyperplastic parathyroids. Highresolution ultrasonography with color Doppler imaging (US/CD) sampling can demonstrate 3 different vascular patterns: (i) glands without vascularization; (ii) hypovascularized glands with a poor or weak Doppler shift (occasional color spots in the hilar/ endonodular region) (a-c); (iii) hypervascularized glands (enlarged feeding artery at the hilum, peripheral arc of vascularity and/or ray-like endonodular vessels) (d-f). Asterisk indicates transversal process of cervical vertebra; arrowhead points to colloidal nodule of thyroid gland. $\mathbf{T}=$ thyroid; $\mathbf{V}=$ cervical vertebra.

vantage over other imaging techniques (e.g., single-photon emission computed tomography [SPECT]-scintigraphy, computed tomography $[\mathrm{CT}]$ and magnetic resonance [MR]). Glandular volume (in cubic millimeters) is calculated using the formula of an irregular ellipsoid $\left(4 /{ }_{3} \pi \times 1 / 2\right.$ anteroposterior diameter $\times 1 / 2$ laterolateral diameter $\times 1 / 2$ craniocaudal diameter). The increase in glandular volume should mean an increased PTH secretion and a worsening of $\operatorname{sHPT}(1,15)$. Indeed, there is a weak linear relationship between glandular volume and serum levels of intact parathyroid hormone (i-PTH) (16). The correlation between glandular volume and histological features demonstrates that glands $<500 \mathrm{~mm}^{3}$ show diffuse or multinodular and polyclonal hyperplasia, whereas glands $>500 \mathrm{~mm}^{3}$ are affected by monoclonal nodular hyperplasia in $80 \%$ of cases (17).

Both in primary hyperparathyroidism and in SHPT, the increase in volume of parathyroid glands is associated with a widespread increase in vascularity, evident at histology and at US/CD sampling (18-22) (Fig. 2). Usually, in CD, we can distinguish 3 different patterns: (i) glands with no Doppler signal; (ii) hypovascularized glands with a poor or weak Doppler signal, represented by occasional color spots in the hilar/endonodular region; and (iii) hypervascularized glands, with an enlarged feeding artery at the hilum, a peripheral arc of vascularity and/or ray-like endonodular vessels. Occasionally, it is possible to record a spectral signal at the hilum; in these cases, the peak systolic velocity is about $15-30 \mathrm{~cm} / \mathrm{s}(11,19)$. Sonographic characteristics of parathyroid glands are summarized in Table II.

There is no evidence that suggests any correlation between vascular pattern and glandular function (20-23). A hyper-
TABLE II

SONOGRAPHIC CHARACTERISTICS OF PARATHYROID GLANDS (11, 13-19)

Definition of

- Two diameters $>5 \mathrm{~mm}$

hyperplasia at US

Gray-scale pattern

- Normal glands: indistinguishable from thyroid parenchyma

- Hyperplastic glands: hypoechoic, volume $<500 \mathrm{~mm}^{3}$

- Nodular glands: hypoechoic. Rare cysts or calcifications. Volume $>500 \mathrm{~mm}^{3}$

Vascular pattern at US/CD

- Glands without vascularization

- Hypovascularized glands with a poor or weak Doppler shift (occasional color spots in the hilar/ endonodular region)

- Hypervascularized glands (enlarged feeding artery at the hilum, peripheral arc of vascularity and/or ray-like endonodular vessels)

Histology of excised glands

- Volume $<500 \mathrm{~mm}^{3}$ : usually hyperplastic glands

- Volume $>500 \mathrm{~mm}^{3}$ : nodular hyperplasia in $80 \%$ of cases 


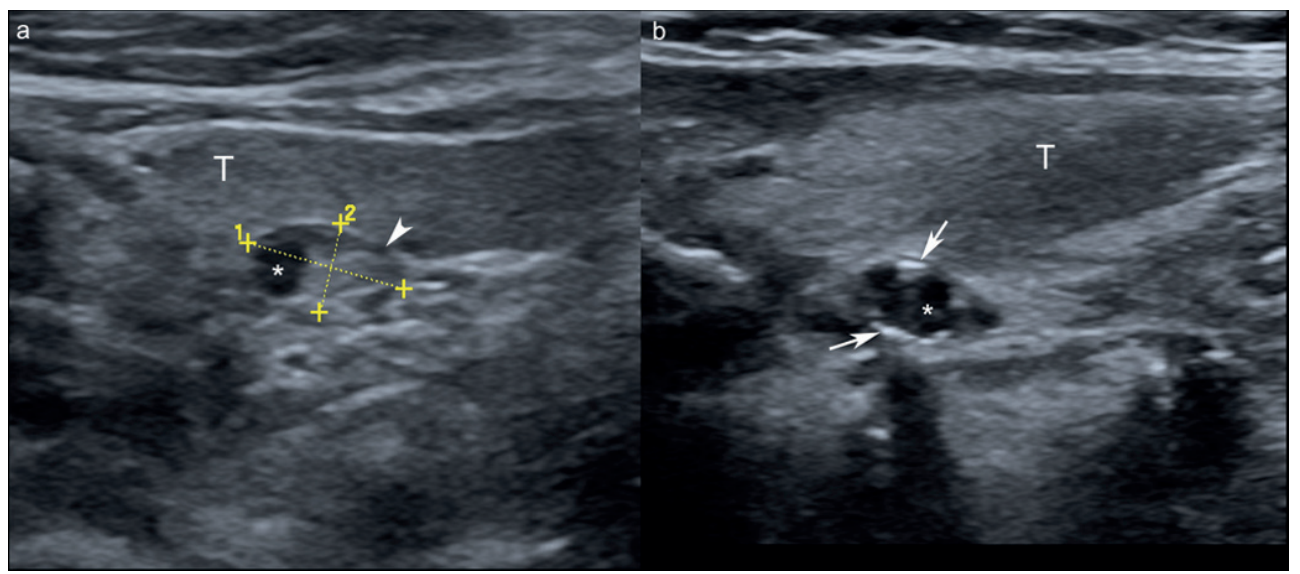

Fig. 3 - Gray-scale parameters of secondary hyperparathyroidism progression. a, b) After longterm treatment with conventional therapy and cinacalcet, parathyroid gland can show involutive phenomena such as hyperechogenicity (arrowhead), cystic lesions (asterisk) or calcifications (white arrows). $\mathrm{T}=$ thyroid lobe.

functioning gland $>500 \mathrm{~mm}^{3}$ is hypervascularized but may be hypovascularized or avascularized due to inadequate sampling, artefacts, deep localization in the neck or mediastinum and cinacalcet therapy.

\section{HIGH-RESOLUTION ULTRASOUND AND DIAGNOSIS OF SECONDARY HYPERPARATHYROIDISM}

Diagnosis and treatment of sHPT are based on serum i-PTH levels and on the parameters of mineral metabolism, though the determination of PTH can pose some problems because of the heterogeneity of the molecule and the important biological, preanalytical and postanalytical variability (23).

Although i-PTH and biochemical data are pivotal in defining clinical aspects of SHPT, they do not give information about the morphology and volume of the gland(s). The primary role of US/CD in SHPT should be to integrate the clinical diagnosis by defining the number and volume of hyperplastic glands, although the international guidelines do not state when and why to perform US/CD. Our policy is to perform a US/CD scan when serum i-PTH levels are $>400 \mathrm{pg} / \mathrm{mL}$ for at last 3 determinations in 3 months in dialysis or predialysis patients. In clinical practice, it is not uncommon to find that patients with CKD stage 5 have i-PTH $>400 \mathrm{pg} / \mathrm{mL}$ but no hyperplastic glands at US/CD. In these cases, the mismatch between morphological and biochemical data may be due to (i) the inadequacy of therapy, (ii) the lack of therapeutic compliance, (iii) a false US/CD negative or (iv) an analytical mistake in evaluating serum i-PTH levels. In these cases, if the increase in serum i-PTH levels is confirmed by further dosages, the regimen has been checked and the patient's compliance has been reinforced, then SESTAMIBIscintigraphy or hybrid techniques such as SPECT-CT should be performed to exclude the presence of ectopic glands undetectable with US/CD for their location. Nevertheless, scintigraphy is more invasive, expensive and time-consuming, and its sensitivity and specificity in SHPT are lower than those of US/CD $(17,19,24)$. Therefore, US/CD must be considered the first-line imaging diagnostic tool in the clinical diagnosis of SHPT, whereas scintigraphy has a complementary role. US/CD should be repeated once a year in patients receiving conservative or dialytic therapy with high levels of serum i-PTH in order to evaluate an initial or nodular hyperplasia. The best solution would be to have the expertise in an ultrasound section in the nephrology unit in order to be directly involved in the diagnosis, clinical follow-up and treatment of their own patients.

\section{ASSESSMENT OF THE PROGRESSION OF SECONDARY HYPERPARATHYROIDISM}

Serum i-PTH changes do not provide an accurate evaluation of severity of sHPT. In fact, serum i-PTH does not correlate with glandular masses in patients treated with phosphate binders, vitamin D or analogues and cinacalcet - while morphofunctional parameters (volume and perfusional pattern) show a progression related to the duration and severity of the uremic state $(15,16)$.

Parameters to be considered for the assessment of SHPT progression include (i) the echogenicity of the gland (Fig. 3a); (ii) gland diameter $(25,26)$ and volume (19); (iii) the appearance of involutive cystic phenomena as anechoic areas with no vascularization; and (iv) the evidence of fibrocalcifications (Fig. 3b) (22). Gray-scale parameters must be completed with $\mathrm{CD}$ sampling to characterize the vascular pattern. Changes in morphological and perfusional patterns are indicative of the functional state of the gland. Consequently, the morphological changes followed by serial controls can evaluate the progression of sHPT and efficacy of the pharmacological treatment. 


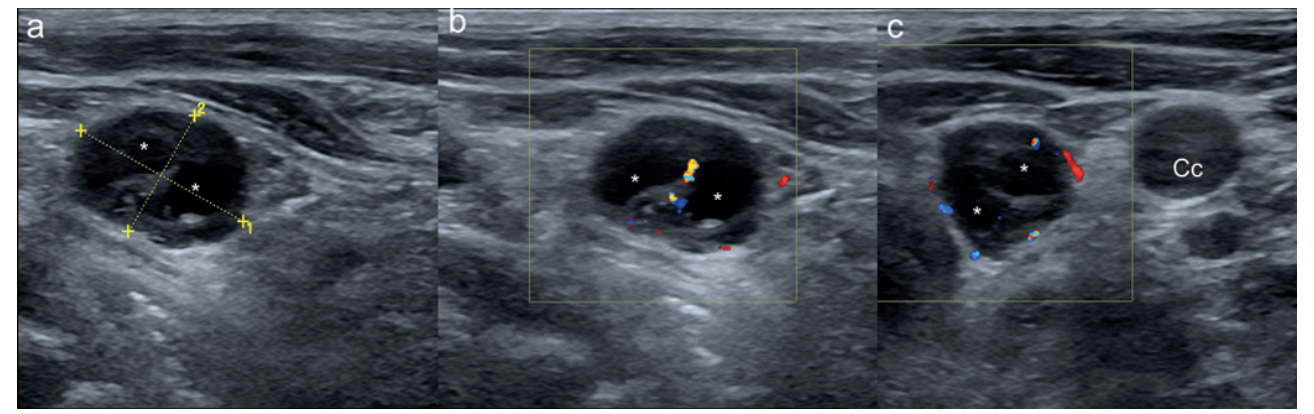

Fig. 4 - Morphological changes of parathyroid glands after cinacalcet. Before cinacalcet, the gland was hypoechoic with a solid appearance. a-c) After 18 months of cinacalcet and conventional therapy, the gland's volume was reduced and areas of cystic degeneration appeared (asterisk). A diffuse hypovascularization was evident. $\mathbf{C c}=$ common carotid artery.

\section{US/CD TO DEFINE SURGICAL TIMING OF SHPT}

Presurgical imaging in sHPT is less important than in primary hyperparathyroidism. In fact, in sHPT, hyperplasia does not involve equally all parathyroid glands, so in any case to excise the hyperplastic glands, it is mandatory to perform a conventional explorative cervicotomy. Conversely, in primary hyperparathyroidism, the first choice surgical technique is the videoscopic parathyroidectomy, in which it is pivotal to know the exact location of the adenoma to reduce surgical time and associated risks (27-30). As in sHPT there is a wide variation in glandular volume, the overall sensitivity of US/CD is lower than in primary hyperparathyroidism and does not exceed $74 \%-75 \%(<50 \%$ in the localization of parathyroids $<500 \mathrm{~mm}^{3},>90 \%$ in glands $\left.\geq 500 \mathrm{~mm}^{3}\right)(17,19)$. Based on these observations, the role of US/CD should not therefore be to localize the glands but instead to define the surgical timing. In fact, according to Kidney Disease Improving Global Outcomes (KDIGO) guidelines, parathyroidectomy is indicated in patients with CKD stages 3-5D when serum i-PTH, Ca, P and Ca x P product are no longer controlled by conventional therapy (31), but also when US/CD shows 1 or more nodular hyperplastic parathyroids $\geq 500 \mathrm{~mm}^{3}(32,33)$.

\section{ULTRASOUND-GUIDED PARATHYROID GLAND ALCOHOLIZATION}

Ultrasound percutaneous ethanol injection therapy (PEIT) is an interventional procedure used in advanced SHPT to induce chemical ablation of the parathyroid glands larger than $1 \mathrm{~cm}$ in diameter or $0.5 \mathrm{~cm}^{3}$ in calculated volume (34). The interval between initial and subsequent additional ethanol injections varies depending upon the protocol. Glands are selectively destroyed by injection of $90 \%$ ethanol with $1 \%$ lidocaine under US/CD guidance. For safety, the initial injection volume should not exceed $80 \%$ of the calculated volume of the gland. Gray-scale US is used to confirm that the needle tip is in the center of the gland, whereas CD is used to establish the residual blood supply and the need for additional ethanol injections (34). To date, no serious adverse effects related with this practice have been reported (35), whereas several reports suggest a significant reduction of i-PTH in up to $89 \%$ of cases. Efficacy of PEIT in maintenance hemodialysis (MHD) patients with sHPT is related to the number of hyperplastic parathyroid glands. The best results in terms of efficacy rate, remission period and risk of relapse are obtained when the treatment is limited to patients with only 1 hyperplastic gland $>0.5 \mathrm{~cm}$ (36). However, while the short-term results of PEIT are promising, the longer-term ones remain controversial because they are not comparable with parathyroidectomy. Nowadays, the only indication to PEIT is recurrent SHPT untreatable with parathyroidectomy. Percutaneous injection of calcitriol has also been proposed to reduce glandular mass via hyperstimulation of VDRs (37), however this method has yielded poor results to date (38).

\section{MORPHOLOGICAL CHANGES OF PARATHYROID GLANDS: ASSESSING EFFICACY OF CONVEN- TIONAL THERAPY AND CALCIMIMETICS}

Glandular volume is directly related to the number and volume of glands detected, but in severe sHPT, it is variable and not always correlated with serum i-PTH levels (15). This observation suggests that the biggest glands tend to disengage from receptor control mechanisms (i.e., the up-regulation of $\mathrm{CaR}$ and VDR) and grow independently. The release of PTH in this condition is not proportional to total glandular volume. The combination of conventional therapy (phosphate binders, vitamin D or analogues) with cinacalcet marks a clear reversal in the progression of the disease: serum PTH levels are reduced, mineral metabolism is stabilized, US/CD analysis reveals progressive changes in 
volume and vascularization is reduced after 12-18 months $(13,39)$. The regression of hyperplasia is like a "chemical parathyroidectomy," which is associated with a satisfactory control of mineral metabolism and delays the need for surgery (40). In the biggest glands $\left(\geq 500 \mathrm{~mm}^{3}\right)$, volume reduction $(>60 \%)$ is associated with a loss of vascular signal, progressing to complete disappearance of vascularization. The majority of glands develop involutive phenomena (cystic-like lesions), whereas in glands with volume $<500 \mathrm{~mm}^{3}$, the volume reduction is accompanied by a structural change toward hyperechogenicity, as if the relationship between cellularity and stromal adipose tissue had been reversed (Fig. 4) (41). This suggests that calcimimetic treatment is able to modulate the biological response of the cell with uncontrolled proliferation via a direct stimulation of the CaR and VDR expression (42). The synergic action of calcimimetic and vitamin $\mathrm{D}$ with phosphate binders on physiological receptor stimulation could explain the regression of morphological SHPT. It has yet to be determined whether this regression occurs because of an increase in cell apoptosis, as suggested by some experimental studies $(43,44)$, or because of the direct action of the calcimimetic on vessels or adipocytes.

\section{FUtURE DIRECTIONS}

Epidemiological studies are needed to establish how US/CD could change the management of SHPT and why it should be repeated in patients with high levels of serum i-PTH. In our series of 395 consecutive CKD stage 5D patients, a concordance between i-PTH levels and US/CD features was evident in $73.4 \%$. Vice versa, in $26.6 \%$ of cases, there was an evident mismatch: $19.3 \%$ of patients with i-PTH $\leq 400 \mathrm{pg} / \mathrm{mL}$ had glandular hyperplasia, whereas $48.5 \%$ of patients with i-PTH $>400 \mathrm{pg} / \mathrm{mL}$ did not present hyperplasia. In these subgroups of patients, serum i-PTH levels were unable to define the grading of sHPT. In contrast, by comparing i-PTH values to US/CD features we have been able to distinguish those cases in which the treatment is adequate despite the glandular hyperplasia, from those in which i-PTH is high due an inadequate pharmacological treatment or lack of compliance. Considering the feasibility and repeatability of US/CD, an yearly exam would be useful to image an initial or nodular hyperplasia, to evaluate the progression of hyperplasia and to aid clinical, pharmacological and surgical strategies.

Financial support: The authors did not receive any financial support for this review.

Conflict of interest statement: The authors do not have any conflict of interest.

Address for correspondence:

Mario Meola, MD

Nephrology Division

Department of Clinical and Experimental Medicine

University of Pisa, Hospital of Cisanello

Via Paradisa 2

IT-56127 Pisa, Italy

mmeola@int.med.unipi.it

\section{References}

1. Drüeke TB. Cell biology of parathyroid gland hyperplasia in chronic renal failure. J Am Soc Nephrol. 2000;11(6):1141-1152.

2. Wetmore JB, Quarles LD. Calcimimetics or vitamin D analogs for suppressing parathyroid hormone in end-stage renal disease: time for a paradigm shift? Nat Clin Pract Nephrol. 2009;5(1):24-33.

3. Parfitt AM. The hyperparathyroidism of chronic renal failure: a disorder of growth. Kidney Int. 1997;52(1):3-9.
4. Fukagawa M. Cell biology of parathyroid hyperplasia in uremia. Am J Med Sci. 1999;317(6):377-382.

5. Arnold A, Brown MF, Ureña P, Gaz RD, Sarfati E, Drüeke TB. Monoclonality of parathyroid tumors in chronic renal failure and in primary parathyroid hyperplasia. J Clin Invest. 1995;95(5):2047-2053.

6. Salem MM. Hyperparathyroidism in the hemodialysis population: a survey of 612 patients. Am J Kidney Dis. 1997;29(6): 862-865.

7. Afonso S, Santamaría I, Guinsburg ME, et al. Chromosomal aberrations, the consequence of refractory hyperparathy- 
roidism: its relationship with biochemical parameters. Kidney Int Suppl. 2003;85(85):S32-S38.

8. Fukagawa M, Kitaoka M, Yi H, et al. Serial evaluation of parathyroid size by ultrasonography is another useful marker for the long-term prognosis of calcitriol pulse therapy in chronic dialysis patients. Nephron. 1994;68(2):221-228.

9. Katoh N, Nakayama M, Shigematsu T, et al. Presence of sonographically detectable parathyroid gland can predict resistance to oral pulsed-dose calcitriol treatment of secondary hyperparathyroidism. Am J Kidney Dis. 2000;35(3): 465-468.

10. Bannister LH, Berry MM, Collins P, et al. eds. Gray's anatomy. New York, NY: Churchill Livingstone; 1995:17.

11. Steward DL, Hainston JA. Development and surgical anatomy of the thyroid compartment. In: Terris DJ, Gourin CG, eds. Thyroid and parathyroid diseases. New York, NY: Thieme; 2009:11-17.

12. Solbiati L, Charboneau JW, Osti W, et al. The thyroid gland. In: Rumack CM, Wilson SR, Charboneau JW, eds. Diagnostic ultrasound. 3rd ed. Chap. 21. St Louis, MO: Elsevier Mosby; 2005:735-770.

13. Meola M, Petrucci I, Barsotti G. Long-term treatment with cinacalcet and conventional therapy reduces parathyroid hyperplasia in severe secondary hyperparathyroidism. Nephrol Dial Transplant. 2009;24(3):982-989.

14. Pavlovic D. Prevention and treatment of secondary hyperparathyroidism: still a challenge for the nephrologist? Nephrol Dial Transplant. 2003;18(90005):S45-S46.

15. Indridason OS, Heath H III, Khosla S, Yohay DA, Quarles LD. Non-suppressible parathyroid hormone secretion is related to gland size in uremic secondary hyperparathyroidism. Kidney Int. 1996;50(5):1663-1671.

16. Matsuoka S, Tominaga $\mathrm{Y}$, Sato $\mathrm{T}$, et al. Relationship between the dimension of parathyroid glands estimated by ultrasonography and the hyperplastic pattern in patients with renal hyperparathyroidism. Ther Apher Dial. 2008;12(5):391-395.

17. Périé $\mathrm{S}$, Fessi $\mathrm{H}$, Tassart $\mathrm{M}$, et al. Usefulness of combination of high-resolution ultrasonography and dual-phase dual-isotope iodine 123/technetium Tc 99m sestamibi scintigraphy for the preoperative localization of hyperplastic parathyroid glands in renal hyperparathyroidism. Am J Kidney Dis. 2005;45(2):344-352.

18. Martins P, Schmitt F, Almeida H, Frazão JM. Evaluation of parathyroid gland angiogenesis in chronic kidney disease associated with secondary hyperparathyroidism. Nephrol Dial Transplant. 2008;23(9):2889-2894.

19. Meola M, Petrucci I, Calliada F, et al. Presurgical setting of secondary hyperparathyroidism using high-resolution sonography and color Doppler. Ultraschall Med. 2011;32 (S 01)(Suppl 1):S74-S82.

20. Calliada F, Sala G, Conti MP, et al. [Clinical applications of color-Doppler: the parathyroid glands.] Article in Italian. Radiol Med. 1993;85(5 Suppl 1):114-9.
21. Lane MJ, Desser TS, Weigel RJ, Jeffrey RB Jr. Use of color and power Doppler sonography to identify feeding arteries associated with parathyroid adenomas. AJR Am J Roentgenol. 1998;171(3):819-823.

22. Gooding GAW, Clark OH. Use of color Doppler imaging in the distinction between thyroid and parathyroid lesions. Am J Surg. 1992;164(1):51-56.

23. Souberbielle JC, Boutten A, Carlier M-C, et al. Inter-method variability in PTH measurement: implication for the care of CKD patients. Kidney Int. 2006;70(2):345-350.

24. Taillefer R, Boucher Y, Potvin C, Lambert R. Detection and localization of parathyroid adenomas in patients with hyperparathyroidism using a single radionuclide imaging procedure with technetium-99m-sestamibi (double-phase study). J Nucl Med. 1992;33(10):1801-1807.

25. Vulpio C, Bossola M, De Gaetano A, et al. Ultrasound patterns of parathyroid glands in chronic hemodialysis patients with secondary hyperparathyroidism. Am J Nephrol. 2008;28(4): 589-597.

26. Matsuoka S, Tominaga Y, Sato T, et al. Relationship between the dimension of parathyroid glands estimated by ultrasonography and the hyperplastic pattern in patients with renal hyperparathyroidism. Ther Apher Dial. 2008;12(5):391-395.

27. Fraser WD. Hyperparathyroidism. Lancet. 2009;374(9684): 145-158.

28. Elder GJ. Parathyroidectomy in the calcimimetic era. Nephrology (Carlton). 2005;10(5):511-515.

29. Jeanguillaume C, Ureña P, Hindié E, et al. Secondary hyperparathyroidism: detection with I-123-Tc-99m-Sestamibi subtraction scintigraphy versus US. Radiology. 1998;207(1): 207-213.

30. Mariani G, Gulec SA, Rubello D, et al. Preoperative localization and radioguided parathyroid surgery. J Nucl Med. 2003;44(9):1443-1458.

31. Kidney Disease: Improving Global Outcomes (KDIGO) CKDMBD Work Group. KDIGO clinical practice guideline for the diagnosis, evaluation, prevention, and treatment of Chronic Kidney Disease-Mineral and Bone Disorder (CKD-MBD). Kidney Int Suppl. 2009;(113):S1-S130.

32. Schömig M, Ritz E. Management of disturbed calcium metabolism in uraemic patients: 2. Indications for parathyroidectomy. Nephrol Dial Transplant. 2000;15 Suppl 5:25-29.

33. Tominaga Y, Matsuoka S, Sato T. Surgical indications and procedures of parathyroidectomy in patients with chronic kidney disease. Ther Apher Dial. 2005;9(1):44-47.

34. Fukagawa M, Kitaoka M, Tominaga Y, Akizawa T, Kurokawa K. Selective percutaneous ethanol injection therapy (PEIT) of the parathyroid in chronic dialysis patients: the Japanese strategy. Nephrol Dial Transplant. 1999;14(11): 2574-2577.

35. Mauz PS, Stiegler M, Holderried M, Brosch S. Complications of ultrasound guided percutaneous ethanol injection therapy of the thyroid and parathyroid glands. Ultraschall Med. 2005;26(2):142-145. 
36. Koiwa F, Kakuta T, Tanaka R, Yumita S. Efficacy of percutaneous ethanol injection therapy (PEIT) is related to the number of parathyroid glands in haemodialysis patients with secondary hyperparathyroidism. Nephrol Dial Transplant. 2007;22(2):522-528.

37. Shiizaki K, Negi S, Mizobuchi M, et al. Effect of percutaneous calcitriol injection therapy on secondary hyperparathyroidism in uraemic patients. Nephrol Dial Transplant. 2003;18(90003) (Suppl 3):iii42-iii46.

38. de Barros Gueiros JE, Chammas MC, Gerhard R, et al. Percutaneous ethanol (PEIT) and calcitrol (PCIT) injection therapy are ineffective in treating severe secondary hyperparathyroidism. Nephrol Dial Transplant. 2004;19(3):657-663.

39. Komaba H, Nakanishi S, Fujimori A, et al. Cinacalcet effectively reduces parathyroid hormone secretion and gland volume regardless of pretreatment gland size in patients with secondary hyperparathyroidism. Clin J Am Soc Nephrol. 2010;5(12):2305-2314.

40. Kakuta T, Tanaka R, Kanai G, et al. Can cinacalcet replace parathyroid intervention in severe secondary hyperparathyroidism? Ther Apher Dial. 2009;13(Suppl 1):S20-S27.
41. Meola M, Petrucci I, Colombini E, Barsotti G. Use of ultrasound to assess the response to therapy for secondary hyperparathyroidism. Am J Kidney Dis. 2011;58(3): 485-491.

42. Mendoza FJ, Lopez I, Canalejo R, et al. Direct upregulation of parathyroid calcium-sensing receptor and vitamin $D$ receptor by calcimimetics in uremic rats. Am J Physiol Renal Physiol. 2009;296(3):F605-F613.

43. Mizobuchi M, Ogata H, Hatamura I, et al. Activation of calcium-sensing receptor accelerates apoptosis in hyperplastic parathyroid cells. Biochem Biophys Res Commun. 2007;362(1):11-16.

44. Lomonte C, Vernaglione L, Chimienti D, et al. Does vitamin $\mathrm{D}$ receptor and calcium receptor activation therapy play a role in the histopathologic alterations of parathyroid glands in refractory uremic hyperparathyroidism? Clin J Am Soc Nephrol. 2008;3(3):794-799.

Accepted: August 01, 2012 